Adıyaman Üniversitesi Sağlık Bilimleri Dergisi, 2020;6(2):132-139

doi:10.30569.adiyamansaglik.661009

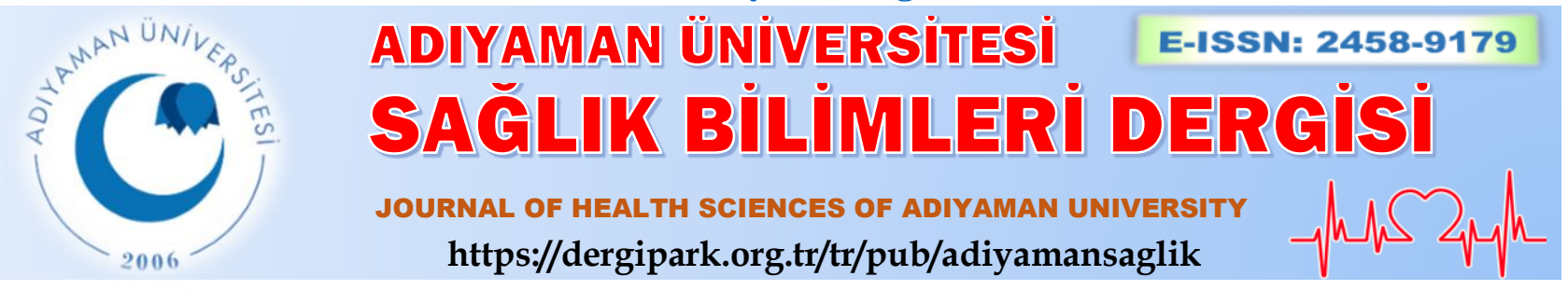

Özgün Araştırma/Research Article

\title{
Anterior estetik restorasyonların yaşam kalitesi üzerine etkisinin değerlendirilmesi
}

\section{Evaluation of the effect of anterior aesthetic restorations on the quality of life}

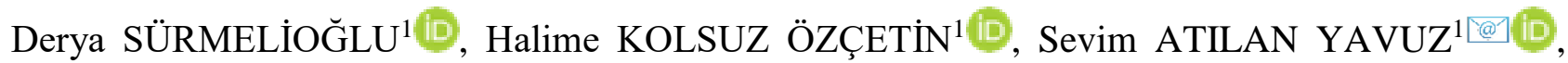

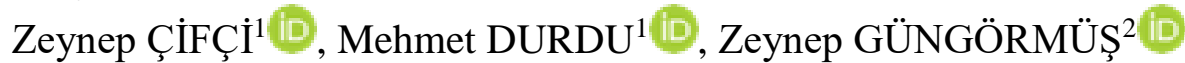

${ }^{1}$ Gaziantep Üniversitesi, Diş Hekimliği Fakültesi, Restoratif Diş Tedavisi Anabilim Dalı, 27310, Gaziantep-Türkiye

${ }^{2}$ Gaziantep Üniversitesi, Sağlık Bilimleri Fakültesi, Halk Sağlığı Hemşireliği Anabilim Dalı, 27410, Gaziantep-Türkiye

Atıf gösterme/Cite this article as: Sürmelioğlu D, Kolsuz Özçetin H, Atılan Yavuz S, Çifçi Z, Durdu M, Güngörmüş Z. Anterior estetik restorasyonların yaşam kalitesi üzerine etkisinin değerlendirilmesi. ADYÜ Sağlık Bilimleri Derg. 2020;6(2):132-139. doi:10.30569.adiyamansaglik.661009

Öz

Amaç: Bu çalışmanın amacı anterior bölgede yapılan estetik restorasyonların hastaların yaşam kalitesi üzerine olan etkisinin Ağı Sağlığı Etki Profili (Oral Health Impact Profile, OHIP-14) ölçeği ile değerlendirilmesidir.

Gereç ve Yöntem: Gaziantep Üniversitesi Diş Hekimliği Fakültesi Restoratif Diş Tedavisi Anabilim Dalı kliniğine anterior bölgedeki estetik şikayetleri sebebi ile başvuran 60 hasta çalışmaya dahil edildi. Estetik olarak rehabilite edilen hastalara OHIP-14 ölçeği tedaviden önce, tedaviden hemen sonra ve 1,6 ay sonrası uygulanmış elde edilen skorlar çift tekrarlayan ölçümlü varyans analizi ve Friedmann, ikili karşılaştırma Willcoxon testi ile değerlendirilmiştir.

Bulgular: Tüm OHIP-14 ölçek toplam skorlarının değerlendirilmesi sonucu, tedavi öncesi elde edilen veriler ile tedaviden hemen sonra, 1 . ay ve 6 . ay sonra elde edilen veriler arasında anlamlı farklılık bulundu $(p<0,05)$. Yine tüm tedavi sonrası elde edilen veriler arasında da anlamlı farklılık vard $1(p<0,05)$.

Sonuç: Anterior estetik restorasyonlar uzun dönemde, kişilerin yaşam kalitesi üzerine pozitif yönde etki sağlamıştır.

Anahtar Kelimeler: Estetik restorasyon; OHIP-14; Yaşam kalitesi ölçeği.

\begin{abstract}
Aim: The aim of this study was to evaluate the effect of aesthetic restorations on the quality of life of the patients using the Oral Health Impact Profile (OHIP14) scale.

Materials and Methods: Sixty patients who applied to the Restorative Dentistry Department of Gaziantep University Faculty of Dentistry with aesthetic complaints in the anterior region were included in the study. The OHIP-14 scale was administered to the aesthetically rehabilitated patients before, after immediately and 1, 6 months after the treatment and scores were obtained. Data were evaluated by two-way repeated analysis of variance and Friedmann, Willcoxon tests.

Results: As a result of evaluating the total scores of the whole OHIP-14 scale, a significant difference was found between the data obtained before treatment and immediately after treatment, at 1 month and 6 months $(p<0.05)$. There was a significant difference between the data obtained after all treatment $(p<0.05)$.

Conclusion: Anterior esthetic restorations, has provided a positive impact on people's quality of life in the long term.
\end{abstract}

Keywords: Aesthetic restorations; OHIP-14; Quality of life.

Yazışma Adresi/Address for Correspondence: Sevim ATILAN YAVUZ, Gaziantep Üniversitesi, Diş Hekimliği Fakültesi, Restoratif Diş Tedavisi Anabilim Dalı, 27310, Gaziantep-Türkiye, E-mail: dtsevimatilan@ gmail.com

Geliş Tarihi/Received:18.12.2019 Kabul Tarihi/Accepted:25.04.2020 $\quad$ Yayım Tarihi/Published online:30.08.2020

Bu eser, Creative Commons Atıf-GayriTicari 4.0 Uluslararası Lisansı ile lisanslanmıştır. Telif Hakk1 @ 2020 Adıyaman Üniversitesi Rektörlüğü 


\section{Giriş}

Estetiğin günden güne önem kazanması ile hastaların birçoğu fonksiyonel şikayetlere kıyasla estetik problemler ile diş hekimlerine başvurmaya başlamışlardır. Tanım olarak estetik içerisinde birçok kavramı barındirmaktadır. $\mathrm{Bu}$ kavramlar arasında dişlerin şekil, renk, boyut, yüzey yapısı, çevre diş dokularla uyumu ve orta hat yer almaktadır. Daimî dentisyonda en çok karşılaşılan estetik problemler; diastema, kırık, şekil ve pozisyon anomalileridir. $\mathrm{Bu}$ anomaliler hastalarda fonksiyon, fonasyon, estetik gibi problemlere yol açtığı için fiziksel, psikolojik ve sosyal yönden etkilenen hastaların yaşam kalitesini düşürmektedir. Genç erişkin hastalarda bu tablo daha dramatik izlenmektedir çünkü ergenlik döneminde fiziksel görünüm büyük endişe teşkil etmektedir. ${ }^{1}$ Ağız ve yüz, fiziksel görünümün ve çekiciliğin en önemli kriterleri arasında yer almaktadır. ${ }^{2-5} \mathrm{Bu}$ nedenle, hastaların ihtiyaç ve taleplerini, algılarını ve tutumlarını ve tedaviden beklentilerini daha iyi anlamak için hasta tabanlı araştırma ve karşılaştırmalı analiz yapılması gerekmektedir. $\mathrm{Bu}$ tür çalışmalar hekimlerin ve hastaların memnuniyet ve yaşam kalitesini iyileştirmelerini sağlayabilmektedir.

Yaşam kalitesi, Dünya Sağlık Örgütü (WHO) tarafindan bireylerin içinde bulunduğu durumlardaki tam iyilik hali olarak tanımlanmıştır. ${ }^{6}$ Diş Hekimliğinde yapılan uygulamalarda hem hasta memnuniyeti ölçümleri hem de yaşam kalitesi ölçümleri son yıllarda kullanılmaya başlanmıştır. ${ }^{7}$ Yaşam kalitesi ölçümlerinin bilinen en büyük avantaj1, soruların hastalar tarafindan tedavi sonrasi alınan cevaplar doğrultusunda oluşturulmasidır. Bunun sonucunda tedavisi bitmiş hastalarda meydana gelebilecek fonksiyonel, psikolojik ve sosyal etkiler doğrudan değerlendirilmektedir. ${ }^{8,9}$ Hasta memnuniyeti son derece karmaş1k, değerlendirilmesi zor olduğundan dolayı birçok hekim bu konuda bilgi ve desteğe ihtiyaç duymaktadır. ${ }^{10}$ Hekimlere yardımcı olması açısından çeşitli ölçekler geliştirilmiş olup yaşam kalitesi ölçümlerinde en çok kullanılanlardan biri de Ağı Sağlığı Etki Profilidir (Oral Health Impact Profile, OHIP).
OHIP fonksiyonel limitasyon, fiziksel ağnı ve yetersizlik, psikolojik rahatsızlık ve sosyal yetersizlik gibi alanları içeren sorulardan oluşmuş bir ölçektir. Bu ölçek için Slade ve Spencer ${ }^{11}$ tarafindan 64 hasta üzerinde dental problemler değerlendirilmiş 7 farklı alanda 49 adet soru oluşturulmuştur. Sonrasında 1997 yılında Slade tarafindan OHIP-14 ölçeği, 14 soru içerecek şekilde kısaltılarak en çok kullanılan formu oluşturulmuştur. ${ }^{12} \mathrm{Bu}$ ölçekte bulunan her sorunun 5 adet cevabı bulunmakla birlikte hasta tarafindan verilen bu cevaplar 0 ile 4 arasında skorlanmaktadır. $\mathrm{Bu}$ cevaplar hiçbir zaman, nadiren, bazen, siklıkla ve her zaman' şeklindedir. ${ }^{12}$ OHIP-14 2006 yilında Mumcu ve ark. ${ }^{13}$ tarafindan Türkçeye çevrilmiş, Türkiye'de diş hekimliğinde yapılacak çalışmalarda kullanılabileceğini belirtmişlerdir.

$\mathrm{Bu}$ çalışmadaki amacımız; genç yetişkin bireylerde yapılan ön bölge estetik rehabilitasyonların tedavi öncesi ve sonrasının OHIP-14 ölçeği ile yaşam kalitesine olan etkisini değerlendirmektir.

\section{Gereç ve Yöntem}

Bu çalışma İlgili Üniversitenin Etik Kurulu tarafindan 2019/313 protokol numarasi ile onaylanmış, çalışmaya katılan tüm hastalardan bilgilendirilmiş onay formu alınmıştır. Çalışma Helsinki Deklarasyonunda belirtilen etik kurallara uygun olarak yapılmıştır.

\section{Hasta seçimi}

Gaziantep Üniversitesi Diş Hekimliği Fakültesi Restoratif Diş Tedavisi kliniğine estetik problemler nedeni ile başvuran hastalar arasından 15-25 yaş aralığındaki 60 hasta dahil edilmiştir. Bu çalışmaya dahil olma kriterleri hastalarda; ön bölgede yer alan diastema, kırık diş, çapraşıklık, renk ve şekil anomalileri gibi şikayetlerin var olmasıdır. Non-koopere, oral hijyeni kötü, dişeti problemi olan hastalar ve gebeler çalışmaya dahil edilmemiştir.

\section{Tedavi grubu prosedürleri}

Çalışmaya dahil edilmek üzere belirlenen hastaların klinik ve radyografik muayeneleri yapılmıştır. Tedaviye başlanmadan önce hastalardan verilen OHIP-14 anketini 
cevaplandırmaları istenmiştir. Çapraşıklık, kırık diş, diastema, renk ve şekil bozukluğu gibi şikayetleri olan hastalara diş rengine uygun kompozit dolgu materyali seçilerek işleme başlanmıştır. Ağız içi ortamdan, tükürükten, kandan, dişeti oluğu sıvısından izolasyonu sağlamak için Vivadent OptraDam Plus (Ivoclar, Inc. Ny, USA) kullanılmıştır. $\% 37$ 'lik fosforik asit, mine yüzeyi ile 15 sn işlem gördükten sonra 10 sn boyunca uygulanan hava su spreyi ile diş yüzeyinden uzaklaştırılmıştır. Bunun sonucunda yüzey pürüzlülüğü arttırılmış olup adezyon güçlendirilmiştir. Dentin yüzeyinin açığa çıktığ 1 vakalarda ise bond sistemlerinin selfetch modu kullanılmıştır. Optimum koşullar sağlandıktan sonra üretici talimatları doğrultusunda G-Premio Bond (GC Europe, Inc. Lueven, Belgium) diş yüzeylerine uygulanmıştır. Hava-su spreyi ile inceltilen bond tabakası 20 sn boyunca VALO LED (Ultradent, Inc. South Jordan, Utah) 1ş1k cihazı ile polimerize edilmiştir. İdeal 1 şı ortamında diş rengine uygun renkte seçilen kompozit materyali uygulanmaya hazır hale getirilmiştir. Estetik dolgu materyali olan G- aenial anterior kompozit (GC Europe, Inc. Lueven, Belgium) uygulanıp 20 sn boyunca üretici talimatlarına uygun șekilde polimerize edilmiştir. Tüm işlemler bittikten sonra SofLex Bitim \& Cila Diskleri (3M, Inc. Minnesota, USA) kullanılarak yüzey polisajı yapılmıştır. Restorasyonların bitimini takiben OHIP-14 anketi tekrarlanmıştır.

\section{Takip randevuları}

Restorasyonların tamamlanmasından 1 ve 6 ay sonra hastalar kliniğge tekrar çağrılarak OHIP-14 anketini doldurmaları istenmiştir. Hastaların klinik ve radyografik muayeneleri yapılarak ağız hijyeni ve restorasyonların durumu kontrol edilmiștir. Muayene, hastanın tedavisini gerçekleştiren hekim tarafından yapılmıştır.

Çalışmada kullanılan OHIP-14 anketinin soruları tablo 1'de gösterilmiștir. OHIP ölçüm yapacağı konular açısından, fonksiyonel sınırlamalar, fiziksel ağrı, ruhsal sıkıntı, fiziksel yetersizlik, sosyal yetersizlik, ruhsal yetersizlik ve engel olarak yedi kategoriye ayrılmaktadır.

Tablo 1. OHIP-14 ölçeği.

\begin{tabular}{|c|c|c|}
\hline \multirow{2}{*}{$\begin{array}{l}\text { Fonksiyonel } \\
\text { sinırlamalar }\end{array}$} & OH1 & $\begin{array}{l}\text { Dişleriniz, ağzınız veya protezleriniz ile ilgili problemler nedeni ile herhangi bir } \\
\text { kelimeyi telaffuz etmekte sorununuz oldu mu? }\end{array}$ \\
\hline & $\mathrm{OH} 2$ & $\begin{array}{l}\text { Dişleriniz, ağzınız veya protezleriniz ile ilgili problemler nedeni ile tat alma } \\
\text { hissinizin bozulduğunu hissediyor musunuz? }\end{array}$ \\
\hline \multirow{2}{*}{ Fiziksel ağrı } & $\mathrm{OH} 3$ & $\begin{array}{l}\text { Dişleriniz, ağzınız veya protezleriniz ile ilgili problemler nedeni ile ağzınızda ağrılı } \\
\text { bir durum yaşadınız mı? }\end{array}$ \\
\hline & $\mathrm{OH} 4$ & $\begin{array}{l}\text { Dişleriniz, ağzınız veya protezleriniz ile ilgili problemler nedeni ile yemek yemeyi } \\
\text { rahatsız edici buldunuz mu? }\end{array}$ \\
\hline \multirow{2}{*}{ Ruhsal sıkıntı } & OH5 & $\begin{array}{l}\text { Daha önceden, dişleriniz, ağzınız veya protezlerinizle ilgili bilinç ve bilgiye sahip } \\
\text { miydiniz? }\end{array}$ \\
\hline & OH6 & $\begin{array}{l}\text { Dişleriniz, ağzınız veya protezleriniz ile ilgili problemler nedeni ile gerginlik } \\
\text { hissettiniz mi? }\end{array}$ \\
\hline \multirow{2}{*}{$\begin{array}{l}\text { Fiziksel } \\
\text { yetersizlik }\end{array}$} & $\mathrm{OH} 7$ & $\begin{array}{l}\text { Dişleriniz, ağzınız veya protezleriniz ile ilgili problemler nedeni ile diyetinizin tatmin } \\
\text { edici olmadığı oldu mu? }\end{array}$ \\
\hline & $\mathrm{OH} 8$ & $\begin{array}{l}\text { Dişleriniz, ağzınız veya protezleriniz ile ilgili problemler nedeni ile yemeğinizi } \\
\text { yarıda bırakmak zorunda kaldınız mı? }\end{array}$ \\
\hline \multirow{2}{*}{$\begin{array}{l}\text { Sosyal } \\
\text { yetersizlik }\end{array}$} & OH9 & $\begin{array}{l}\text { Dişleriniz, ağzınız veya protezleriniz ile ilgili problemler nedeni ile gevşemede } \\
\text { zorlandığınız oldu mu? }\end{array}$ \\
\hline & $\mathrm{OH} 10$ & $\begin{array}{l}\text { Dişleriniz, ağzınız veya protezleriniz ile ilgili problemler nedeni ile utandığınız bir } \\
\text { durum oldu mu? }\end{array}$ \\
\hline \multirow{2}{*}{$\begin{array}{l}\text { Ruhsal } \\
\text { yetersizlik }\end{array}$} & OH11 & $\begin{array}{l}\text { Dişleriniz, ağzınız veya protezleriniz ile ilgili problemler nedeni ile diğer insanlara az } \\
\text { da olsa asabi davrandığınız oldu mu? }\end{array}$ \\
\hline & $\mathrm{OH} 12$ & $\begin{array}{l}\text { Dişleriniz, ağzınız veya protezleriniz ile ilgili problemler nedeni ile her zaman } \\
\text { yaptığınız işinizi yapmada herhangi bir zorluk yaşadınız mı? }\end{array}$ \\
\hline \multirow{2}{*}{$\begin{array}{l}\text { Engel } \\
\text { (handikap) }\end{array}$} & OH13 & $\begin{array}{l}\text { Dişleriniz, ağzınız veya protezleriniz ile ilgili problemler nedeni ile genelde hayatın } \\
\text { daha az tatmin edici olduğu hissine kapıldınız mı? }\end{array}$ \\
\hline & $\mathrm{OH} 14$ & $\begin{array}{l}\text { Dişleriniz, ağzınız veya protezleriniz ile ilgili problemler nedeni ile fonksiyonlarınızı } \\
\text { tümüyle yapamayacak duruma geldiniz mi? }\end{array}$ \\
\hline
\end{tabular}


Her soru için hiçbir zaman, nadiren, bazen, sıklıkla ve çok sık olmak üzere beş cevap seçeneği vardır. OHIP-14 TR ölçeğinin değerlendirilmesinde Likert yanıt sistemi kullanılmıştır ${ }^{12}$. Bu sistemde, "hiç" ifadesi 0 ile, "nadiren" ifadesi 1 ile, "bazen" ifadesi 2 ile, "sıklıkla" ifadesi 3 ile ve "çok sık" ifadesi 4 ile belirtilmiştir. Değerlendirmede OHIP-14 katılımcının her bir maddeye verdiği yanıtların toplam skoru gösterir. OHIP-14 sonuç değeri $0^{\prime}$ dan 56' ya kadar değişmektedir. Toplam skor arttıkça problemin şiddetlendiği ve yaşam kalitesinin düştüğü sonucuna varılmıştır. ${ }^{14}$

\section{İstatistiksel analiz}

Çalışmada elde edilen bulgular değerlendirilirken, istatistiksel analizler için normal dağılıma uygunluk kontrolünde Shaphiro Wilk testi kullanılmıştır. İkiden fazla bağımlı ölçümün karşılaştırılmasında normal dağılıma sahip olmayan değişkenler için Freidman devamında Willcoxon, normal dağılan değişkenler için tekrarlayan ölçümlü varyans analizi devamında paired-t testleri kullanılmıştır. İstatistiksel analizler için SPSS 22.0 Windows paket programı kullanılmış ve $p<0.05$ istatistiksel olarak anlamlı kabul edilmiştir.

\section{Bulgular}

Tüm OHIP-14 ölçek toplam skorlarının değerlendirilmesi sonucu, tedavi öncesi elde edilen veriler $\left(\mathrm{T}_{1}\right)$ ile tedaviden hemen sonra $\left(\mathrm{T}_{2}\right)$, 1. ay $\left(\mathrm{T}_{3}\right)$ ve 6 . ay $\left(\mathrm{T}_{4}\right)$ sonra elde edilen veriler arasinda anlaml farklılık bulundu $\left(\mathrm{T}_{1^{-}}\right.$ $\left.\mathrm{T}_{2}, \mathrm{~T}_{1}-\mathrm{T}_{3}, \mathrm{~T}_{1}-\mathrm{T}_{4} ; p<0,05\right)$. Yine tüm tedavi sonrasi elde edilen veriler arasında da anlamlı farkl11.k vard $1\left(\mathrm{~T}_{2}-\mathrm{T}_{3}, \mathrm{~T}_{2}-\mathrm{T}_{4}, \mathrm{~T}_{3}-\mathrm{T}_{4} ; p<0,05\right)$.

Sorular1 siniflama dahilinde değerlendirdiğimizde;

1. Fonksiyonel limitasyon $\left(S_{1}\right)$ ile ilgili sorularda tedavi öncesi, sonrası ve takipleri arasında anlamli farkl11.k vard1 $\left(\mathrm{S}_{1} \mathrm{~T}_{1}-\mathrm{S}_{1} \mathrm{~T}_{2}\right.$, $\left.\mathrm{S}_{1} \mathrm{~T}_{1}-\mathrm{S}_{1} \mathrm{~T}_{3}, \mathrm{~S}_{1} \mathrm{~T}_{1}-\mathrm{S}_{1} \mathrm{~T}_{4} ; p<0,05\right)$. Tedavi sonras1 elde edilen veriler arasinda tedavi sonrası ve 1 ay sonrası verileri arasinda fark bulunmazken $\left(\mathrm{S}_{1} \mathrm{~T}_{2}-\mathrm{S}_{1} \mathrm{~T}_{3} ; p>0,05\right)$ diğer veriler arasında fark vard $\left(\mathrm{S}_{1} \mathrm{~T}_{2}-\mathrm{S}_{1} \mathrm{~T}_{4}, \mathrm{~S}_{1} \mathrm{~T}_{3}-\mathrm{S}_{1} \mathrm{~T}_{4} ; p<0,05\right)$.

2. Fiziksel yetersizlik $\left(\mathrm{S}_{2}\right)$ ile ilgili sorularda tedavi öncesi, sonrası ve takipleri arasında anlaml farkl111k vard $1\left(\mathrm{~S}_{2} \mathrm{~T}_{1}-\mathrm{S}_{2} \mathrm{~T}_{2}\right.$, $\left.\mathrm{S}_{2} \mathrm{~T}_{1}-\mathrm{S}_{2} \mathrm{~T}_{3}, \quad \mathrm{~S}_{2} \mathrm{~T}_{1}-\mathrm{S}_{2} \mathrm{~T}_{4} ; \quad p<0,05\right)$. Yine tüm tedavi sonrası elde edilen veriler arasında da anlamli farkl11.k vard1 $\left(\mathrm{S}_{2} \mathrm{~T}_{2}-\mathrm{S}_{2} \mathrm{~T}_{3}, \mathrm{~S}_{2} \mathrm{~T}_{2}-\mathrm{S}_{2} \mathrm{~T}_{4}\right.$, $\left.\mathrm{S}_{2} \mathrm{~T}_{3}-\mathrm{S}_{2} \mathrm{~T}_{4} ; p<0,05\right)$.

3. Fiziksel ağrı $\left(\mathrm{S}_{3}\right)$ ile ilgili sorularda tedavi öncesi, sonrasi ve takipleri arasında anlaml farkl111k vard1 $\left(\mathrm{S}_{3} \mathrm{~T}_{1}-\mathrm{S}_{3} \mathrm{~T}_{2}, \mathrm{~S}_{3} \mathrm{~T}_{1}-\mathrm{S}_{3} \mathrm{~T}_{3}\right.$, $\left.\mathrm{S}_{3} \mathrm{~T}_{1}-\mathrm{S}_{3} \mathrm{~T}_{4} ; p<0,05\right)$. Yine tüm tedavi sonras1 elde edilen veriler arasında da anlaml farkl111k vard $1\left(\mathrm{~S}_{3} \mathrm{~T}_{2}-\mathrm{S}_{3} \mathrm{~T}_{3}, \mathrm{~S}_{3} \mathrm{~T}_{2}-\mathrm{S}_{3} \mathrm{~T}_{4}, \mathrm{~S}_{3} \mathrm{~T}_{3}-\right.$ $\left.\mathrm{S}_{3} \mathrm{~T}_{4} ; p<0,05\right)$.

4. Psikolojik rahatsızlık $\left(\mathrm{S}_{4}\right)$ ile ilgili sorularda tedavi öncesi, sonrası ve takipleri arasında anlamlı farklılık bulunmamıştır $\left(\mathrm{S}_{4} \mathrm{~T}_{1}-\mathrm{S}_{4} \mathrm{~T}_{2}, \mathrm{~S}_{4} \mathrm{~T}_{1}-\mathrm{S}_{4} \mathrm{~T}_{3}, \mathrm{~S}_{4} \mathrm{~T}_{1}-\mathrm{S}_{4} \mathrm{~T}_{4} ; p<0,05\right)$. Yine tüm tedavi sonrası elde edilen veriler arasında da anlamlı farklilık vard $1\left(\mathrm{~S}_{3} \mathrm{~T}_{2}-\mathrm{S}_{3} \mathrm{~T}_{3}\right.$, $\left.\mathrm{S}_{3} \mathrm{~T}_{2}-\mathrm{S}_{3} \mathrm{~T}_{4}, \mathrm{~S}_{3} \mathrm{~T}_{3}-\mathrm{S}_{3} \mathrm{~T}_{4} ; p<0,05\right)$.

5. Psikolojik yetersizlik $\left(\mathrm{S}_{5}\right)$ ile ilgili sorularda tedavi öncesi, sonrası ve takipleri arasında anlaml1 farkl111k vard1 $\left(\mathrm{S}_{5} \mathrm{~T}_{1}-\mathrm{S}_{5} \mathrm{~T}_{2}\right.$, $\left.\mathrm{S}_{5} \mathrm{~T}_{1}-\mathrm{S}_{5} \mathrm{~T}_{3}, \mathrm{~S}_{5} \mathrm{~T}_{1}-\mathrm{S}_{5} \mathrm{~T}_{4} ; p<0,05\right)$. Tedavi sonras1 elde edilen veriler arasinda 1 ay ve 6 ay sonras1 verileri arasinda fark bulunurken $\left(\mathrm{S}_{5} \mathrm{~T}_{3}-\mathrm{S}_{5} \mathrm{~T}_{4} ; p<0,05\right)$ diğer veriler arasında fark yoktu $\left(\mathrm{S}_{5} \mathrm{~T}_{2}-\mathrm{S}_{5} \mathrm{~T}_{4}, \mathrm{~S}_{5} \mathrm{~T}_{2}-\mathrm{S}_{5} \mathrm{~T}_{3} ; p>0,05\right)$.

6. Sosyal yetersizlik $\left(\mathrm{S}_{6}\right)$ ile ilgili sorularda tedavi öncesi, sonrası ve takipleri arasında anlaml 1 farkl111k vard $1\left(\mathrm{~S}_{6} \mathrm{~T}_{1}-\mathrm{S}_{6} \mathrm{~T}_{2}, \mathrm{~S}_{6} \mathrm{~T}_{1}-\mathrm{S}_{6} \mathrm{~T}_{3}\right.$, $\left.\mathrm{S}_{6} \mathrm{~T}_{1}-\mathrm{S}_{6} \mathrm{~T}_{4} ; p<0,05\right)$. Yine tüm tedavi sonras1 elde edilen veriler arasında da anlaml farkl111k vard1 $\left(\mathrm{S}_{6} \mathrm{~T}_{2}-\mathrm{S}_{6} \mathrm{~T}_{3}, \mathrm{~S}_{6} \mathrm{~T}_{2}-\mathrm{S}_{6} \mathrm{~T}_{4}, \mathrm{~S}_{6} \mathrm{~T}_{3}-\right.$ $\left.\mathrm{S}_{6} \mathrm{~T}_{4} ; p<0,05\right)$.

7. Handikap $\left(\mathrm{S}_{7}\right)$ ile ilgili sorularda tedavi öncesi, sonrası, 1 ay sonrası verileri arasında anlaml 1 farkl1l1k bulunmazken $\left(\mathrm{S}_{7} \mathrm{~T}_{1}-\mathrm{S}_{7} \mathrm{~T}_{2}\right.$, $\left.\mathrm{S}_{7} \mathrm{~T}_{1}-\mathrm{S}_{7} \mathrm{~T}_{3} ; p>0,05\right)$ tedavinin 6 ay sonrasi ile başlangıç skorları arasında anlamlı faklılık vard $1\left(\mathrm{~S}_{7} \mathrm{~T}_{1}-\mathrm{S}_{7} \mathrm{~T}_{4} ; p<0,05\right)$ Yine tedavi sonras1 elde edilen veriler arasında tedavi sonrasi- 1 ay ve 1 ay- 6 ay verileri arasinda fark bulunmazken $\left(\mathrm{S}_{7} \mathrm{~T}_{2}-\mathrm{S}_{1} \mathrm{~T}_{3}, \mathrm{~S}_{7} \mathrm{~T}_{3}-\mathrm{S}_{7} \mathrm{~T}_{4} ; p>0,05\right)$ diğer veriler arasında fark vard $1\left(\mathrm{~S}_{7} \mathrm{~T}_{2}-\mathrm{S}_{7} \mathrm{~T}_{4}\right.$; $p<0,05)$.

Tüm OHIP-14 skorları ortalama değerleri ve arasındaki farklılıklar Tablo 2'de gösterilirken toplam OHIP-14 skorları ayrıca Şekil 1'de gösterilmiştir. 
Tablo 2. Tüm OHIP-14 skorlar1.

\begin{tabular}{lrrrr} 
& Tedavi öncesi & Tedavi sonras1 & $\begin{array}{l}\text { Tedaviden } \\
1 \text { ay sonra }\end{array}$ & $\begin{array}{l}\text { Tedaviden } \\
6 \text { ay sonra }\end{array}$ \\
\hline Fonksiyonel limitasyon & $6,36 \pm 1,74^{\mathrm{a}}$ & $5,30 \pm 1,51^{\mathrm{b}}$ & $5,30 \pm 1,36^{\mathrm{b}}$ & $4,53 \pm 1,37^{\mathrm{bc}}$ \\
Fiziksel ağrı & $2,43 \pm 1,69^{\mathrm{a}}$ & $1,60 \pm 1,36^{\mathrm{b}}$ & $1,23 \pm 1,28^{\mathrm{c}}$ & $1,00 \pm 1,07^{\mathrm{d}}$ \\
Psikolojik rahatsılık & $6,70 \pm 1,41^{\mathrm{a}}$ & $4,03 \pm 1,58^{\mathrm{b}}$ & $3,10 \pm 1,24^{\mathrm{c}}$ & $2,33 \pm 1,28^{\mathrm{d}}$ \\
Fiziksel yetersizlik & $4,83 \pm 1,73^{\mathrm{a}}$ & $5,13 \pm 1,62^{\mathrm{a}}$ & $5,4 \pm 1,95^{\mathrm{ab}}$ & $4,43 \pm 1,88^{\mathrm{ac}}$ \\
Psikolojik yetersizlik & $7,23 \pm 1,11^{\mathrm{a}}$ & $1,80 \pm 1,63^{\mathrm{b}}$ & $1,33 \pm 1,36^{\mathrm{c}}$ & $1,10 \pm 1,29^{\mathrm{c}}$ \\
Sosyal yetersizlik & $5,93 \pm 1,56^{\mathrm{a}}$ & $5,20 \pm 1,52^{\mathrm{b}}$ & $4,66 \pm 1,67^{\mathrm{c}}$ & $4,26 \pm 1,62^{\mathrm{d}}$ \\
Handikap & $4,66 \pm 1,54^{\mathrm{a}}$ & $4,46 \pm 1,57^{\mathrm{a}}$ & $4,20 \pm 1,50^{\mathrm{ab}}$ & $3,86 \pm 1,59^{\mathrm{b}}$ \\
OHIP 14 Total skor & $33,5 \pm 4,73^{\mathrm{a}}$ & $23,0 \pm 4,10^{\mathrm{b}}$ & $21,0 \pm 3,99^{\mathrm{c}}$ & $17,6 \pm 3,33^{\mathrm{d}}$ \\
\hline
\end{tabular}

Satırlardaki farklı harfler, istatistiksel olarak anlamlı farkları göstermektedir.

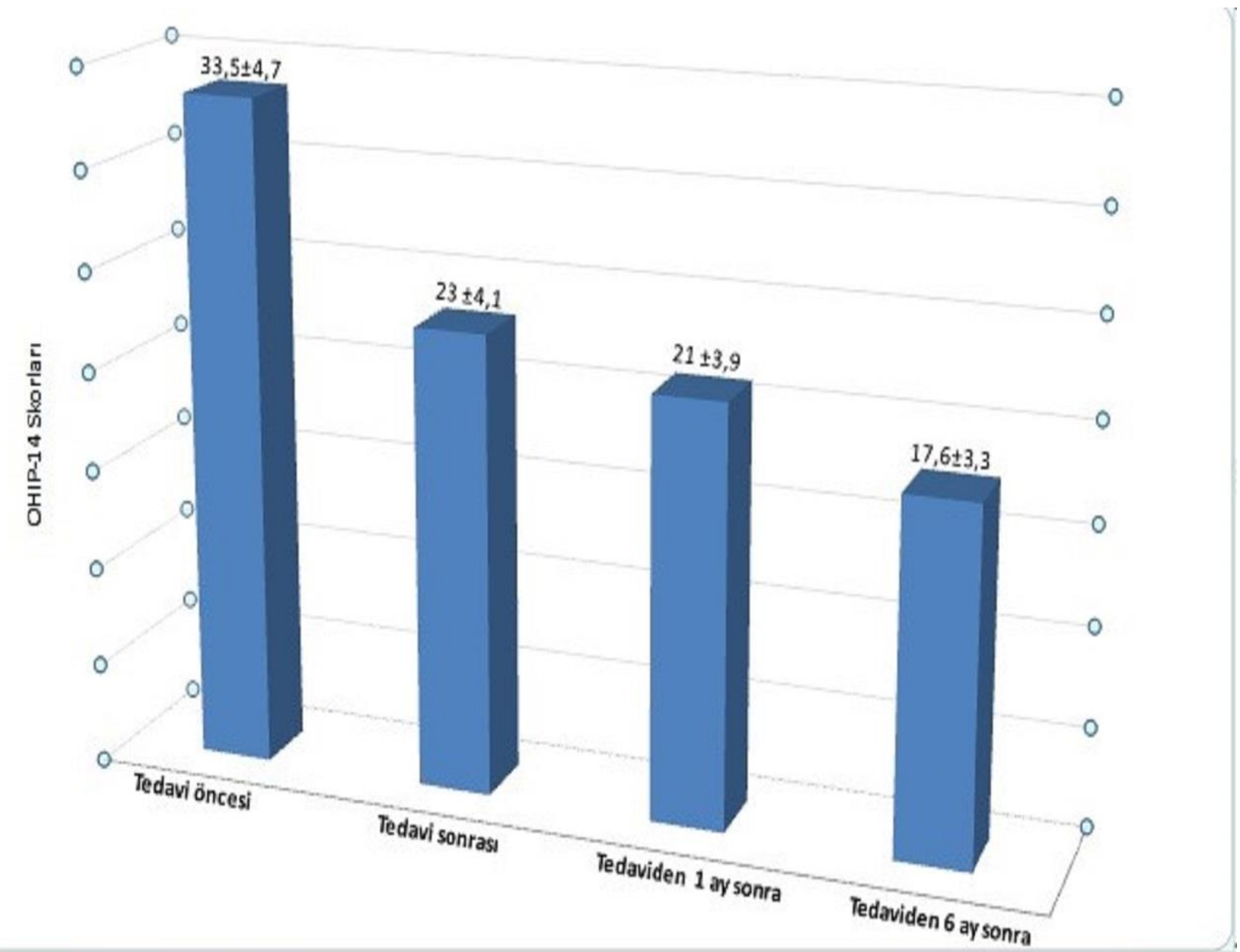

Şekil 1. Toplam OHIP-14 skorları.

\section{Tartıșma}

Gülümseme, sosyal hayatta insan iletişimi, psikolojisi ve bireylerin estetik anlayışında önemli bir faktör olarak yer almaktadır. Günümüzde gelişen teknoloji ile birlikte, bireyler gülüş estetiklerini değiştirmek için farklı tedavi seçenekleri aramaktadır. Gülüş estetiğinin bir parçası olan ön dişlere ait renk, şekil ve konum bozukluklarını tedavi etmeye yönelik yaklaşımlar kişilerin fiziksel, psikolojik ve sosyal durumları için kritik bir rol oynamaktadır. ${ }^{15}$ Kişilerin diş ağrısı çekmesi, yemek yeme ve çiğnemede karşılaştığ 1 zorluklar bireyin günlük aktivitelerini, ruh halini ve sosyal ilişkilerini olumsuz yönde etkilemektedir. ${ }^{16} \mathrm{Bu}$ durum bireyin ruhsal durumunu olumsuz yönde etkilemekle birlikte uzun dönem yaşam kalitesine zarar vermektedir. Ön bölgede bulunan estetik bozukluklar bireylerin hem ikili ilişkilerini hem de toplum içindeki sosyal sorumluluklarını doğrudan ya da dolaylı olarak etkileyebilmektedir. Uygulanacak restorasyonlara karar verilirken temel prensip hastanın beklentileri ve estetik kaygılarıdır. 
$\mathrm{Bu}$ bilgiler 1 şı̆̆ında minimal invaziv restoratif yaklaşımlar, ön bölge estetik restorasyonlarda uygulanması gereken ilk tedavi seçeneğidir. ${ }^{17}$ Seçilen restorasyon materyali, dişte minimum doku kaybına neden olmalı, çevre dokularla biyouyumlu olup ideal mekanik ve morfolojik özelliklere sahip olmalıdır. Direkt adeziv restorasyonlar, dayanıklılık, kalıcılık, estetik, kolay uygulanabilirlik ve diş dokusunu iyi taklit edebilmeleri avantajları arasında yer almaktadır. Ayrıca klinik olarak uzun ömürlü ve ekonomik olmaları gibi özellikleri sebebi ile porselen restorasyonlara kıyasla daha çok tercih edilmektedir. ${ }^{18,19}$

Adeziv diş hekimliğindeki gelişmeler ile fazla preparasyona gerek kalmaksızın, kompozit rezini direkt olarak dişe uygulayarak dişteki çürük ve lezyonları giderme, dişleri yeniden şekillendirme, konum değiştirme ya da diş rengini değiştirme olanağı sağlanmaktadır. ${ }^{20}$

Ön bölge estetik restorasyonlarda kullanılan adeziv sistemlerin klinik başarı oranının yüksek, uzun ömürlü ve uygulanma sırasında sahip olduğu avantajları gösteren önemli çalışmalar litaratürde yer almaktadır. Kullanılacak estetik restoratif materyal komşu dişlere renk ve şekil olarak uyum göstermeli, karşıt ve yan dişlere kontakt sağlamalı; çevre yumuşak dokularla biyouyumlu olmalı, tedavi prosedürleri de gerekli hassasiyet gösterilerek tamamlanmalıdır. ${ }^{21}$ Yaptığımız çalışmada da kullanılan adeziv sistem üretici firma direktiflerine uygun olarak tamamlanmıştır.

Yaşam kalitesi, bireyin içinde bulunduğu dönem ve kültür değerleri içerisinde öne çıkan farklı boyutlarda iyi olma halinin öznel ve nesnel olarak belirlenen kombinasyonudur. Genel olarak yaşam kalitesi kavramı, bireylerin yaşamdan beklentilerini ifade etmekle birlikte, sağlık gibi spesifik konularda da kullanılmaktadır. ${ }^{22}$ Ağız sağlığının bir çok tanımı olmasına rağmen üzerinde en çok uzlaşılan Dolan'ın "bireylerin istedikleri sosyal hayatı sürdürmelerini sağlayan rahat ve fonksiyonel dentisyon" tanımıdır. ${ }^{23}$ Ağız sağlığına bağlı yaşam kalitesi yeni bir kavram olup tanımlanmasında bir çok yaklaşım vardır. Slade ve ark. ${ }^{24}$ ağız sağlığına bağlı yaşam kalitesini "ağız, diş ve çevre dokularının durumunun günlük hayata olan etkileri” olarak tanımlanmıştır. Çalışmamızda kullanılan OHIP-14 ölçeği, bireylerin ağız, diş ve çevre dokuları ile ilgili dile getirdiği rahatsılılı, fonksiyonel yetersizlik gibi durumlara daha detaylı yaklaşmak amaciyla oluşturulan bir ölçektir. OHIP-14 daha çok fiziksel, ruhsal ve sosyal alanlardaki yetersizlikler ile ilgilidir. OHIP-14 ağız sağlığının birey üzerindeki olumsuz etkileri ile ilgilenmektedir. ${ }^{11}$

Literatürde ağı sağlığının yaşam kalitesine etkisini değerlendiren birçok çalışma olmakla birlikte, anterior estetik restorasyonların yaşam kalitesi üzerine etkisini değerlendiren başka bir çalışma bulunmamaktadır.

Hastalardan alınan geri dönüşe göre çalışmamız sonucunda estetik açıdan olumlu sonuçlar elde edilmiştir. Hastalara oral hijyen eğitimi verilmiş ve koruyucu tedaviler sağlanmış olup, 1 . ve 6 . aydaki klinik kontrollerin önemi anlatılmıştır. 1 . ve 6 . aylık takiplerde hastalarda herhangi bir probleme rastlanmamış olmakla birlikte OHIP-14 skorlarında anlamlı bir düşüş görülmüştür.

Özellikle anterior bölge diş sorunlarından dolayı ortaya çıkan ikili ilişkilerde bozulma, çekingenlik, bireyin kendine olan güveninde azalma, anksiyete ve depresif bir ruh hali gibi psikolojik ve sosyal sonuçların yapılan tedaviler ile elimine edildiği görülmüştür. $\mathrm{Bu}$ durumların ortadan kalkması evlilik, kariyer ve eğitim gibi sosyal statüye ilişkin durumların iyileşmesini sağlayacaktır.

Adeziv diş hekimliğinde, minimal invaziv restoratif uygulamalar hekim ve hasta açısından sıklıkla tercih edilmektedir. $\mathrm{Bu}$ tedaviler, dişin morfolojik anomalilerinden kaynaklı sorunların restorasyonu ve hastanın estetik beklentisinin karşılanmasında ekonomik ve konservatif açıdan uygun bir alternatiftir.

Çalışmamızda hasta yaş grubu olarak genç erişkin bireyler tercih edilmiştir. Ancak daha geniş yaş aralığındaki hastaların çalışmaya dahil edilmesi bireylerin dental estetiğe ve etkilerine bakış açısını daha kapsayıcı bir şekilde yansıtabilirdi. Bu durum çalışmamızın limitasyonu sayılabilir. 


\section{Sonuç}

Çalışmamızda ön bölge estetik restorasyonlar kompozit rezin ile tedavi edilerek hastaların yaşam kalitesine olan etkileri değerlendirilmiştir. Elde edilen veriler uygulanan estetik restorasyonların uzun dönemde, kişilerin yaşam kaltesini pozitif yönde etkilediğini ortaya koymuştur. $\mathrm{Bu}$ sonuç yapilacak olan tedaviler için yol gösterici olacaktır. Anterior bölge diş estetiğinin ağız sağlığı ile ilişkili yaşam kalitesi arasındaki etkileşimin daha geniş kitlelerde değerlendirmesi için ek çalışmalara ihtiyaç vardır.

\section{Araştırmanın Etik Boyutu}

$\mathrm{Bu}$ çalışma Gaziantep Üniversitesi Etik Kurulu tarafindan 2019/313 protokol numarası ile onaylanmış, çalışmaya katılan tüm hastalardan bilgilendirilmiş onay formu alınmıştır. Çalışma Helsinki Deklarasyonunda belirtilen etik kurallara uygun olarak yapılmıştır.

\section{Bilgilendirilmiş Onam}

Çalışmaya dâhil edilen tüm hastalardan bilgilendirilmiş onam formunu alınmıştır.

\section{Yazar Katkıları}

Araştırma ve/veya makalenin hipotezini veya fikrini oluşturmada D.S., verilerin düzenlenmesi ve raporlanmasında H.Ö.K, S.Y.A, Z.Ç., M.D. ve Z.G. katk1 sunmuşlardır.

\section{Teșekkürler}

Araştırmaya değerleri görüşleriyle katk1 sağlayan Doç. Dr. Uğur AYDIN'a teşekkür ederiz.

\section{Çıkar Çatışması}

Yazarların herhangi bir çıkara dayalı ilişkisi yoktur.

\section{Araştırma Desteği}

Çalışmayı maddi olarak destekleyen kişi/kuruluş yoktur.

\section{Beyanlar}

$\mathrm{Bu}$ çalışma, 26 - 29 Şubat 2020 tarihleri arasında Kayseri'de düzenlenen 1. Erciyes Üniversitesi Uluslararası Diş Hekimliği
Kongresi'nde (ERDİŞ) sözel bildiri olarak sunulmuştur.

\section{Kaynaklar}

1. Adwere-Boamah J, Curtis DA. A confirmatory factor analysis of a four-factor model of adolescent concerns revisited. Journal of youth and adolescence. 1993;22(3):297-312.

2. Robertson A, Norén JG. Subjective Aspects of Patients with Traumatized Teeth A 15-Year Follow-Up Study. Acta Odontologica Scandinavica. 1997;55(3):142-147.

3. Synnott A. Truth and goodness, mirrors and masks--Part I: A sociology of beauty and the face. The British Journal of Sociology. 1989;40(4):607-636.

4. Baldwin DC. Appearance and aesthetics in oral health. Community dentistry and oral epidemiology. 1980;8(5):244256.

5. Marcenes W, Ryda U. Socio-psychological aspects of traumatic dental injuries. Traumatic Injuries to the Teeth. 2007.

6. Kuyken W. The World Health Organisation quality of life assessment (WHOQOL): position paper from the World Health Organisation. Soc Sci Med. 1995;41:1409-1409.

7. Ersu B, Canay Ş, Akman S. İmplant destekli overdenture ve konvansiyonel tam profitez kullanımının yaşam kalitesine etkisi. SÜ Dişhek Fak Derg. 2007;16(3):39-43.

8. Allen PF. Assessment of oral health related quality of life. Health and Quality of Life outcomes. 2003;1(1):40.

9. Nuttall N, Steele J, Pine C, White D, Pitts N. Adult dental health survey: The impact of oral health on people in the UK in 1998. British Dental Journal. 2001;190(3):121.

10. Cibirka RM, Razzoog M, Lang BR. Critical evaluation of patient responses to dental implant therapy. The Journal of prosthetic dentistry. 1997;78(6):574-581.

11. Slade GD, Spencer AJ. Development and evaluation of the oral health impact profile. Community dental health. 1994;11(1):311

12. Slade GD. Derivation and validation of a short-form oral health impact profile. Community dentistry and oral epidemiology. 1997;25(4):284-290.

13. Mumcu G, Inanc N, Ergun T, et al. Oral health related quality of life is affected by disease activity in Behçet's disease. Oral diseases. 2006;12(2):145-151.

14. Preciado A, Del Río J, Suárez-García M-J, Montero J, Lynch CD, Castillo-Oyagüe R. Differences in impact of patient and prosthetic characteristics on oral health-related quality of life among implant-retained overdenture wearers. Journal of Dentistry. 2012;40(10):857-865.

15. Alkhatib M, Holt R, Bedi R. Prevalence of self-assessed tooth discolouration in the United Kingdom. Journal of dentistry. 2004;32(7):561-566.

16. Petersen PE, Bourgeois D, Ogawa H, Estupinan-Day S, Ndiaye C. The global burden of oral diseases and risks to oral health. Bulletin of the World Health Organization. 2005;83:661-669.

17. Bäckman B, Holm AK. Amelogenesis imperfecta: prevalence and incidence in a northern Swedish county. Community dentistry and oral epidemiology. 1986;14(1):43-47.

18. Manhart J, Chen H, Hamm G, Hickel R. Review of the clinical survival of direct and indirect restorations in posterior teeth of the permanent dentition. Operatıve Dentıstry-University of Washington-. 2004;29:481-508.

19. Macedo G, Raj V, Ritter AV, Swift Jr EJ. Longevity of anterior composite restorations. Journal of Esthetic and Restorative Dentistry. 2006;18(6):310-311.

20. Tuncer D. Direkt Estetik Restorasyonlar. Turkiye Klinikleri Restorative Dentistry-Special Topics. 2017;3(2):66-75.

21. Croll TP, Cavanaugh RR. Augmentation of incisor width with bonded composite resin: another look. Quintessence International. 1990;21(8).

22. Wallander JL, Schmitt M, Koot HM. Quality of life measurement in children and adolescents: issues, instruments, and applications. Journal of clinical psychology. 2001;57(4):571-585. 
23. Dolan TA. Identification of appropriate outcomes for an aging population. Special care in Dentistry. 1993;13(1):35-39.

24. Slade GD. Measuring oral health and quality of life. Chapel Hill. 1997;3. 